\title{
Serratia liquefaciens Group
}

National Cancer Institute

\section{Source}

National Cancer Institute. Serratia liquefaciens Group. NCI Thesaurus. Code $C 124395$.

A non-hierarchical grouping of similar bacteria assigned to the Serratia liquifaciens species. 